\title{
Geographic Variation in Germination Traits in Melia azedarach and Rhaphiolepis umbellata
}

\author{
Tetsuto Abe, Michio Matsunaga
}

The Kyushu Research Center Forestry and Forest Products Research Institute, Kumamoto, Japan.

Email: tetsuabe@ffpri.affrc.go.jp

Received August 26 ${ }^{\text {th }}, 2010$; revised November $26^{\text {th }}, 2010$; accepted December $1^{\text {st }}, 2010$.

\begin{abstract}
Some plant species traits may not be uniform across populations distributed across a wide latitudinal range. This study examined intraspecies variation in the effects of cold stratification on the germination of seeds of two widespread trees, Rhaphiolepis umbellata (Rosaceae) and Melia azedarach (Meliaceae), collected from the subtropical Ogasawara Islands (southern seeds) and the temperate Japan mainland (northern seeds). Under the no-treatment control, the southern seeds germinated faster in $R$. umbellata and achieved a higher germination percentage in M. azedarach. The regional differences in germination performance were reduced by cold stratification. It was reasonable that these germination traits increase fitness under each climate region. Because the remote Ogasawara populations are sufficiently isolated to have developed some distinct characteristics, even common, widespread species may have important conservation value where they exist within insular biota.
\end{abstract}

Keywords: Cold Stratification, Germination Strategy, Latitude, Ogasawara Islands, Widespread Tree Species

\section{Introduction}

Seed germination traits for useful tree species is significant information in silviculture. However, seed germination traits usually contain intraspecific variation such as geographic variation [1]. The isolation of vegetation populations on remote islands leads to high rates of endemism. However, the rate of endemism in insular angiosperm flora is usually within the range of $30 \%$ to $80 \%$ [2]. Thus, a relatively high proportion of native insular plants are widely distributed species common to the closest major land masses. These species have usually been classified by morphological characteristics. However, genetic variation of insular plants has often led to more cryptic divergence of separate populations, even between neighboring islands [3].

The germination requirements of seeds are important determinants of plant fitness [4-6]. For example, the germination of dormant seeds after exposure to a period of low temperature in plants of temperate regions allows seedlings to encounter optimum growing conditions [7]. Similarly, light- or heat-regulated germination systems in tropical woody species enable plants to respond to gap creation [8]. Several studies have shown habitat-specific variations in germination requirements within the same species growing in different localities $[9,10]$ and microhabitats [11]. These findings suggest that adaptation of seed germination requirements can occur in response to slight differences of environmental condition.

The Ogasawara Islands of Japan are subtropical oceanic islands that support a native flora with more than $40 \%$ endemism [12]. Two widespread native species present on the islands are Rhaphiolepis umbellata (Thunb.) $\mathrm{H}$. Ohashi and Melia azedarach L. In this study, to detect evidence for ecological differentiation, we compared the effect of cold stratification on the germination response of these two species in seeds collected from the Ogasawara Islands and from populations on the Japan mainland.

\section{Materials and Methods}

\subsection{Seed Collection}

Rhaphiolepis umbellata and M. azedarach are distributed on both the Ogasawara Islands and the Japan mainland. Seeds of both species from the Ogasawara Islands (southern seeds) were collected on Chichi-jima. Seeds from Japan mainland (northern seeds) were collected from Shimoda (R. umbellata) and Kumamoto and Kochi (M. azedarach; two locations were needed because the 
amount of seeds collected from one site was insufficient for analysis). Kumamoto and Kochi are relatively close (Figure 1) and have similar climates (Figure 2), so the seeds from the two sites were pooled to represent the population of the Japan mainland. Seeds were collected in 2006. Ogasawara has a subtropical climate, whereas Kumamoto and Kochi have a temperate climate. The latitudinal range of Chichi-jima is $27^{\circ} 2^{\prime}-27^{\circ} 5^{\prime} \mathrm{N}$; the latitude of Kumamoto is $32^{\circ} 49^{\prime} \mathrm{N}$, that of Kochi is $33^{\circ} 32^{\prime} \mathrm{N}$, and that of Shimoda is $34^{\circ} 36^{\prime} \mathrm{N}$ (Figure 1). The average temperature of the coldest month is $17.7^{\circ} \mathrm{C}$ on Chichijima, $5.4^{\circ} \mathrm{C}$ in Kumamoto, $6.1^{\circ} \mathrm{C}$ in Kochi, and $7.9^{\circ} \mathrm{C}$ in Shimoda (Figure 2). Ripe seeds of both species were collected from three populations at each northern and southern site. The seeds were used for germination tests soon after removal of the pulp in the laboratory.

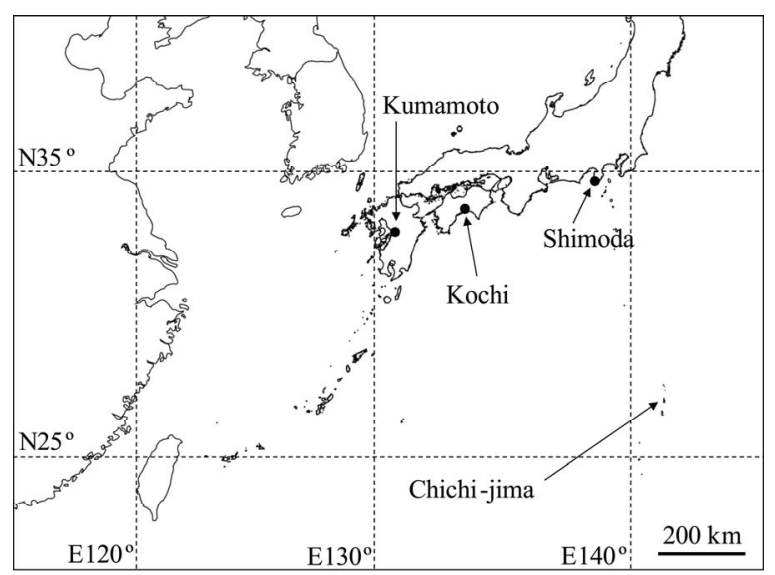

Figure 1. Location of study sites: Chichi-jima in the Ogasawara Islands, and Shimoda, Kumamoto, and Kochi on the Japanese.

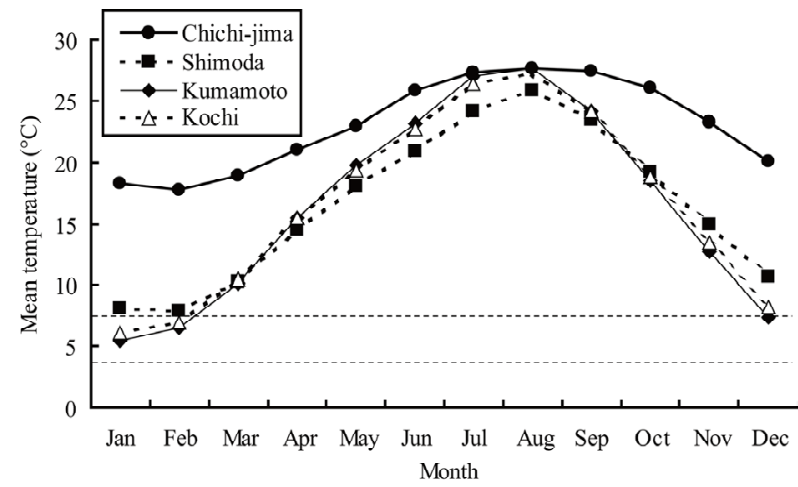

Figure 2. Mean monthly temperatures of Chichi-jima, Shimoda, Kumamoto, and Kochi. Each value is the mean of 30 years of data (1970-2000). The broken horizontal lines represent the temperatures used for cold stratification treatments $\left(3\right.$ and $7^{\circ} \mathrm{C}$ ) in a germination experiment with seeds collected from theselocalities.

\subsection{Seed Stratification and Germination}

The germination test was conducted with two cold stratification treatments $\left(90 \mathrm{~d}\right.$ at either 3 or $\left.7^{\circ} \mathrm{C}\right)$ at dark condition and a no-treatment control $(0 \mathrm{~d})$.

For the germination test, we placed 100 seeds of $M$. azedarach and 100 or 50 seeds of $R$. umbellata into each Petri dish matted a moist filter paper. We used 1,633 seeds of $M$. azedarach collected from 5 trees in Kumamoto and Kochi (6 replications for each treatment), 2,122 seeds of $M$. azedarach from 10 trees on Chichi-jima (8 replications), 1,434 seeds of $R$. umbellata from 7 trees in Shimoda (5 replications), and 3,482 seeds of $R$. umbellata from 16 trees on Chichi-jima (19 replications). The seeds were divided into an equal number for each of the three treatments $\left(3^{\circ} \mathrm{C}\right.$ vs $7^{\circ} \mathrm{C}$ vs control). Remining seeds divided into groups of 100 or 50 were put into a Petri dish and used for the germination test. The seeds were incubated in a cycle of $8 \mathrm{~h}$ light $\left(30^{\circ} \mathrm{C}, 6,000 \mathrm{~lx}\right)$ and $16 \mathrm{~h}$ darkness $\left(20^{\circ} \mathrm{C}\right)$ for $126 \mathrm{~d}$ in a Shimadzu FLI-301NH incubator. The incubation period was finished when the increase in germination rate fell to zero or nearly zero.

Germination was defined as the emergence of the radicle from the seed coat and was checked once a week, when germinated seeds were counted and removed from the dishes. After termination of the germination test, ungerminated seeds were categorized as viable, dead, or sterile by dissection. The germination percentage was calculated from the number of fresh and germinated seeds.

The effects of collection site (Ogasawara vs. Japan mainland) and treatment $\left(3^{\circ} \mathrm{C}\right.$ vs $7^{\circ} \mathrm{C}$ vs control) on germination percentage were examined separately by using a generalized linear model (GLM) with binomial (germinated or not) error structure. The effects of sites and treatments on germination rates (patterns) were separately analyzed by repeated measures ANOVA (RMANOVA). Sites and treatments were regarded as categorical variables. The germination percentage data were arcsin square-root transformed before RMANOVA. All statistical analyses were performed in JMP software [13].

\section{Results}

In $R$. umbellata, the southern seeds germinated significantly faster than the northern seeds in the control (RMANOVA, $\mathrm{F}_{1,22}=2.1, P<0.001$, Figure 3), although there was no significant difference in the final germination percentages (GLM, $\mathrm{G}=0.0, \mathrm{df}=1, P=0.985$ ). The germination rates of southern seeds was significantly faster than that of northern seeds even in each of the two stratification treatments (RMANOVA, $\mathrm{F}_{1,22}=2.4, P<$ 0.001 at $7^{\circ} \mathrm{C} ; \mathrm{F}_{1,22}=9.2, P<0.001$ at $\left.3^{\circ} \mathrm{C}\right)$. Cold stratification increased the germination rate relative to the con- 


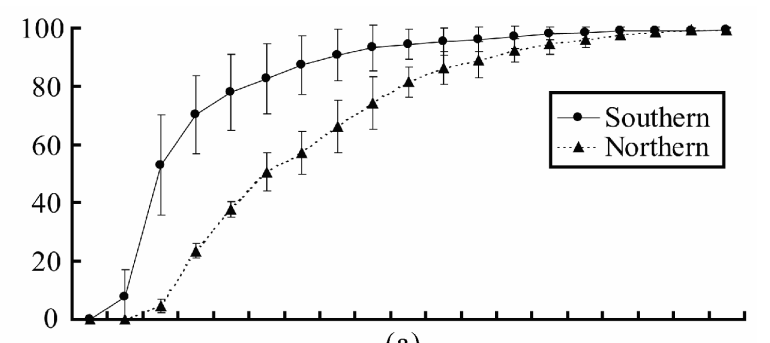

(a)

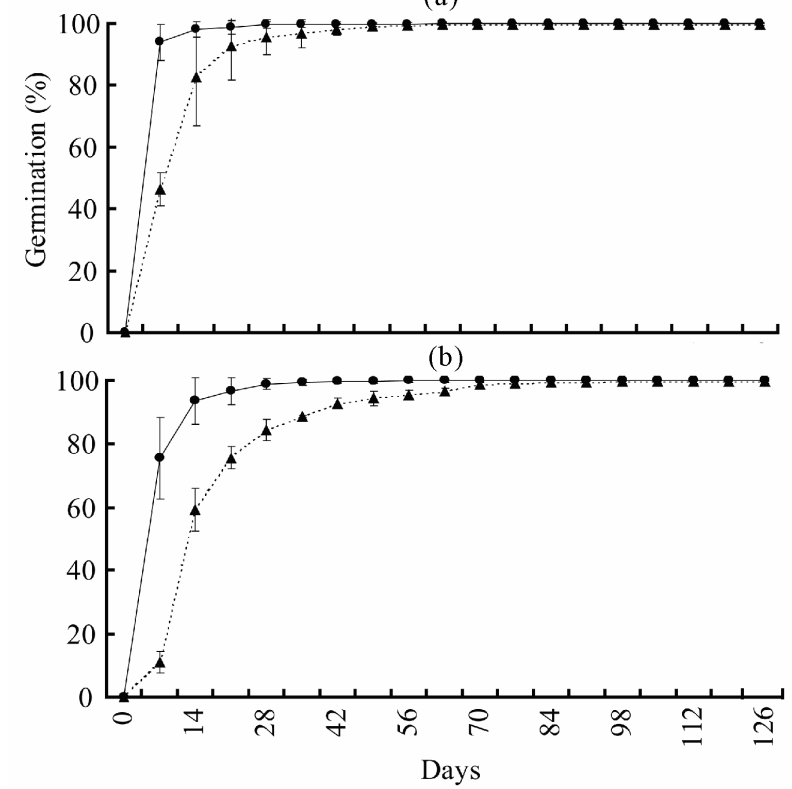

(c)

Figure 3. Germination curves of Rhaphiolepis umbellata seeds collected from southern (Chichi-jima) and northern (Shimoda, Kumamoto and Kochi) populations (a) without cold stratification treatment or subjected to 90 days of cold stratification at (b) $7^{\circ} \mathrm{C}$ or (c) $3^{\circ} \mathrm{C}$. Vertical bars represent one standard deviation either side of the mean.

trol in both the southern seeds (RMANOVA, $\mathrm{F}_{2,54}=4.5$, $P<0.001)$ and the northern seeds (RMANOVA, $\mathrm{F}_{2,12}=$ $26.1, P<0.001)$. Because the germination rate of the northern seeds was so slow in all treatments, cold stratification increased it more than in the southern seeds.

In $M$. azedarach, the southern seeds germinated significantly faster than the northern seeds in the control (RMANOVA, $F_{1,12}=0.4, P=0.049$, Figure 4), but there was no difference in the two cold stratification treatments (RMANOVA, $\mathrm{F}_{1,12}=0.0, P=0.462$ at $7^{\circ} \mathrm{C} ; \mathrm{F}_{1,12}=0.0, P$ $=0.544$ at $3^{\circ} \mathrm{C}$ ). The overall germination percentage of the southern seeds was significantly higher than that of the northern seeds in the control (GLM, $\mathrm{G}=18.1, \mathrm{df}=1$, $P<0.001$ ), but this difference declined with cold stratification. Cold stratification caused a significant increase in the germination percentages (GLM, southern, $F_{2,21}=$ 2.6, $P<0.001$; northern, $\left.\mathrm{F}_{2,15}=2.1, P<0.001\right)$ and germination rates (RMANOVA, southern, $\mathrm{F}_{2,21}=2.6, P<$

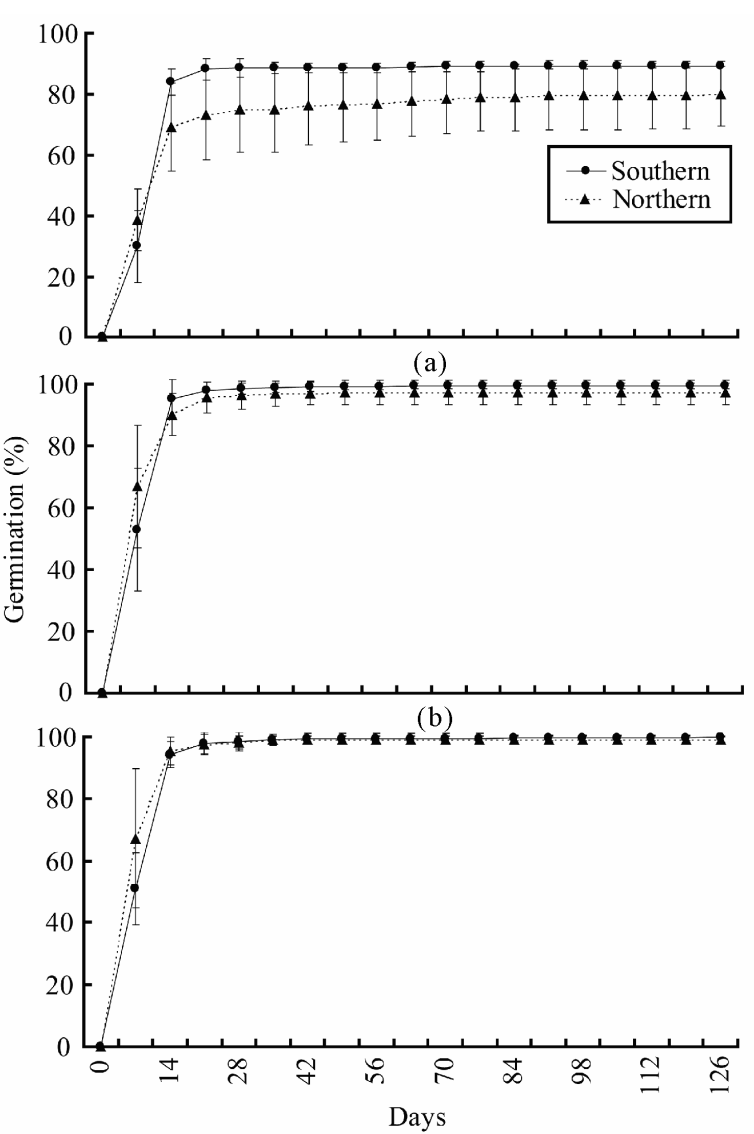

(c)

Figure 4. Germination curves of Melia azedarach seeds collected from southern (Chichi-jima) and northern (Shimoda, Kumamoto, and Kochi) populations (a) without cold stratification treatment or subjected to 90 days of cold stratification at (b) $7^{\circ} \mathrm{C}$ or (c) $3^{\circ} \mathrm{C}$. Vertical bars represent one standard deviation either side of the mean.

0.001 ; northern, $\left.\mathrm{F}_{2,15}=2.1, P<0.001\right)$ of the seeds of both regions.

\section{Discussion}

Without cold stratification treatment, the southern seeds germinated better than the northern seeds of both species. With stratification, this difference diminished, suggesting that low temperature is more important for triggering germination of the northern seeds. The better germination of the southern seeds without cold stratification makes sense as an adaptive trait to increase fitness under the subtropical climate, where the risk of seedling mortality following germination in winter would be much less than in the northern locations. The optimum timing for germination is usually during warmer spring temperatures after the cold of winter, so slow germination would prevent seedling emergence in autumn and exposure of seedlings to winter temperatures [14]. Thus, the 
fact that the northern seeds of $R$. umbellata in all treatments germinated more slowly is reasonable. Similar latitudinal effects in response to cold stratification is also reported from Mediterranean pine species [15]. Although this study detected only the effect of cold stratification, latitudinal differences in other parameters that affect germination, such as light and substrate moisture, may also exist [1].

Both $R$. umbellata and M. azedarach are also distributed in tropical and subtropical continental Asia. Although our data is limited, the results agree with the idea that the germination response to cold stratification in both species changes along a latitudinal gradient in locations linked to major land masses. Alternatively, the remote, isolated populations of the Ogasawara Islands may have developed traits independently of the populations of the main Japanese islands and their temperate climate. Even if seeds from the northern populations occasionally reach the Ogasawara Islands, their dependence on a period of low temperature to break dormancy may decrease their fitness under the subtropical conditions, and they would be unlikely to find an opportunity to occupy suitable habitat. This barrier would act as a reproductive isolation mechanism that can lead to speciation on remote islands. Several studies have shown that restricted gene flow, for example by geographic isolation, is essential for distinct populations to acquire new germination characteristics $[16,17]$.

Further study is required to decide whether these insular plants are sufficiently divergent from those of continental origin to represent different species. However, some common widespread species would display endemic characteristics in isolated populations on remote islands, and thus, even these common species may have important conservation value within insular biota.

\section{Acknowledgements}

We thank Haruto Nomiya, Masato Ohtani, Takaya Yasui, Ryuichi Murase, and Takeshi Sakai for assistance with field work.

\section{REFERENCES}

[1] C. C. Baskin, J. M. Baskin, "Seeds: ecology, biogeography, and evolution of dormancy and germination," Academic Press, 2001.

[2] R. J. Whittaker, J. M. Fernández-Palacios, "Island Biogeography," Oxford University Press, 2007.

[3] J. A. Kwon, C. W. Morde, "Population genetic structure of two rare tree species (Colubrina oppositifolia and Alphitonia ponderosa, Rhamnaceae) from Hawaiian dry and mesic forests using random amplified polymorphic DNA markers," Molecular Ecology, Vol. 11, 2002, pp. 991-
1001. doi:10.1046/j.1365-294X.2002.01497.X

[4] J. L. Harper, "Population biology of plants," Academic Press, 1977.

[5] J. P. Grime, G. Mason, A. V. Curtis, J. Rodman, S. R. Band, M. A. G. Mowforth, A. M. Neal, S. Shaw, "A comparative study of germination characteristics in a local flora," Journal of Ecology, Vol. 69, 1981, pp. 1017 1059. doi:10.2307/2259651

[6] M. Fenner, M (1983) "Seed Ecology," Chapman and Hall, 1983.

[7] H. J. Bouwmeester, C. M. Karssen, "The dual role of temperature in the regulation of the seasonal changes in dormancy and germination of seeds of Polygonum persicaria L.," Oecologia, Vol. 90, 1992, pp. 88-94. doi:10.1007/BF00317813

[8] C. Vázquez-Yanes, A. Orozco-Segovia, "Patterns of seed longevity and germination in the tropical rainforest," Annual Review of Ecology and Systematics, Vol. 24, 1993, pp. 69-87. doi:10.1146/annurev.es.24.110193.000441

[9] J. B. Hacker, M. H. Andrew, J. G. McIvor, J. J. Mott, (1984) "Evaluation in contrasting climates of dormancy characteristics of seed of Digitaria milanjiana," Journal of Applied Ecology, Vol. 31, 1984, pp. 961-969. doi:10.2307/2405060

[10] A. Honěk, Z. Martinková, "Geographic variation in seed dormancy among populations of Echinochloa crus-galli," Oecologia, Vol. 108, 1996, pp. 419-423. doi:10.1007/BF00333716

[11] Y. Shimono, G. Kudo, "Intraspecific variations in seedling emergence and survival of Potentilla matsumurae (Rosaceae) between alpine fellfield and snowbed habitats," Annals of Botany, Vol. 91, 2003, pp. 21-29. doi:10.1093/aob/mcg002

[12] T. Abe, "Threatened pollination systems in native flora of the Ogasawara (Bonin) Islands," Annals of Botany, Vol. 98, 2006, pp. 317-334. doi:10.1093/aob/mcl117

[13] J. Sall, L. Creighton, A. Lehman, "JMP start statistics, 3rd ed.," SAS Institute, 2004.

[14] S. E. Meyer, S. B. Monsen, "Habitat-correlated variation in mountain big sagebrush (Artemisia tridentata ssp. vaseyana) seed germination patterns," Ecology, Vol. 72, 1991, pp. 739-742. doi:10.2307/2937214

[15] A. Skordilis, C. A. Thanos, "Seed stratification and germination strategy in the Mediterranean pines Pinus brutia and P. halepensis," Seed Science Research, Vol. 5, 1995, pp. 151-160. doi:10.1017/S0960258500002774

[16] A. M. Ellison, "Interspecific and intraspecific variation in seed size and germination requirements of Sarracenia (Sarraceniaceae)," American Journal of Botany, Vol. 88, 2001, pp. 4429-437. doi:10.2307/2657107

[17] A. Mathias, E. Kisdi, "Adaptive diversification of germination strategies," Proceedings of the Royal Society of London B, Vol. 269, 2001, pp. 151-155. doi:10.1098/rspb.2001.1867 